UDC 519.246 .5

DOI: $10.22363 / 2312-9735-2018-26-1-74-83$

\title{
Modeling of Extreme Precipitation Fields on the Territory of the European Part of Russia
}

\author{
E. Yu. Shchetinin*, N. D. Rassakhan ${ }^{\dagger}$ \\ * FGU "All-Russian research institute \\ on problems of civil defence and emergencies of Emergency Control Ministry of Russia" \\ 7 Davydkovskaya St., Moscow, 121352, Russian Federation \\ † Department of Applied Mathematics \\ Moscow State Technology University "STANKIN" \\ 3 a Vadkovsky Ln., Moscow, 127055, Russian Federation
}

\begin{abstract}
Present work is devoted to the study and development of space-time statistical structures of extreme type modeling with the use of the max-stable processes. The theory of one-dimensional extremal values and its extension to the two-dimensional case are considered and for that maxstable processes are introduced and then the main parametric families of max-stable processes (Schlather, Smith, Brown-Resnick, and Extremal-t) are presented. By modifying the maximum likelihood method, namely using the paired likelihood function, parameter estimates were obtained for each of the models whose efficiency was compared using the Takeuchi information criterion (TIC).

Resulting models are coherent with classical extreme value theory and allow consistent treatment of spatial dependence of rainfall. We illustrate the ideas through data, based on daily cumulative rainfall totals recorded at 14 stations in central European part of Russia for period 1966-2016 years. We compare fits of different statistical models appropriate for spatial extremes and select the model that is the best for fitting our data. The method can be used in other situations to produce simulations needed for hydrological models, and in particular for the generation of spatially heterogeneous extreme rainfall fields over catchments. It is shown that the most successful model for the data we studied is the model from the extremal-t family with the Whittle-Matern correlation function.
\end{abstract}

Key words and phrases: spatial modeling, extreme rainfall, max-stable processes, extreme value theory, spatial structures of statistical dependence, pairwise likelihood function

\section{Introduction}

The rapidly growing number of various natural and man-made disasters that previously were considered extremely rare indicates that the global climate change of the Earth is becoming obvious. Observable in various regions of the world and in particular in Russia, hurricanes, rainfalls and other natural disasters bring human casualties and substantial material damage to states and their economies. Therefore it is necessary to develop new methods of resisting the impacts of different environmental disasters, including comprehensive measures for forecasting, preventing and adapting the population to extreme situations. The study of regional climate change peculiarities that take place in connection with global warming is a priority area of modern international research projects. Important place in this area is given to the study of changes in the frequency and intensity of extreme weather events, including extreme precipitation, as it often leads to serious economic, environmental and human losses.

According to recent studies significant increase in the frequency of extreme events including rainfall is expected as a result of global and regional climate change. The archives of long-term accumulated observations and numerical model calculations of hydrometeorological parameters make it possible to study general patterns of spatiotemporal variability of extreme precipitation in Russia, caused by both environmental and anthropogenic factors over the historical observation period and to calculate the projections of their possible future changes.

Received $1^{\text {st }}$ December, 2017. 
Spatial modeling methods is a popular approach for studying extreme events in environmental applications. Numerous scientific publications (like [1-3]) on this subject are engaging extreme value theory (EVT) and extreme processes to the analysis of environmental problems.

Present work is devoted to the study and development of precipitation models in European Russia for the period 1966-2016 with the aim of constructing a short-term precipitation forecast in a given region exceeding the normative indices. The study of regularities of long-term variability of extreme precipitation on the territory of Russia is aimed at the development of long-term forecasts. At the same time, such studies are important for the subsequent solution of many applied problems, including long-term planning of regional economic development.

\section{Extreme Value Theory}

Extreme value theory is based on Fisher-Tippett-Gnedenko theorem [2] that states the existence of normalized maxima's marginal distribution for sequence of i.i.d. random variables. If such distribution $H(x)$ exists and is non-degenerate then it satisfies requirements of max-stable distributions $H^{n}\left(\alpha_{n} x+\beta_{n}\right)=H(x)$ for $n>1$ and $\alpha_{n}>0$ and $\beta_{n} \in \mathbb{R}, x \in \mathbb{R}^{1}$. Such distributions can be written in alternative form

$$
H(x)=\exp \left\{\left[-\left\{1+\xi\left(\frac{x-\mu}{\sigma}\right)\right\}_{+}^{-\frac{1}{\xi}}\right]\right\},
$$

where $a_{+}=\max (a, 0),-\infty<\mu<\infty$ is location parameter, $\sigma>0$ is scale parameter and $-\infty<\xi<\infty$ is shape parameter. Last equation represents generalized extreme value (GEV) distribution [1] because it includes Weibull distribution $(\xi<0)$, Gumbel distribution $(\xi=0)$ and Frechet distribution $(\xi>0)$. Case $\xi=0$ is interpreted as limiting $\xi \rightarrow 0$.

Another approach to order statistic modeling known as the threshold approach is bound to previous one. Following Pickands theory [1] under suitable conditions and for a sufficiently high threshold $u$, the upper tail distribution of a wide class of random variables $X$ can be well approximated by

$$
G(x)=1-\operatorname{Pr}(X>x)=1-\zeta\left\{1+\xi\left(\frac{x-u}{\tau+\xi u}\right)\right\}_{+}^{-\frac{1}{\xi}}
$$

where $x>u, \tau+\xi u>0,-\infty<\xi<\infty$ and $\zeta(u)=\operatorname{Pr}(X>u)$. Here $\zeta(u)$ is the probability that the threshold $u$ is exceeded, and $\tau$ and $\xi$ are respectively scale and shape parameters determining the distribution of exceedances corresponding to those of the limiting distribution of maxima. The parametrization of the generalized Pareto distribution (GPD), whose survivor function appears in the braces on the right part of equation is different from the usual one and has the advantage that the parameters $\tau$ and $\xi$ do not depend on the choice of threshold $u$.

\section{Max-Stable Processes}

Using of max-stable processes [3] is an extension of extreme value theory applied to spatio-temporal precipitation fields. Let $Y_{1}, Y_{2}, \ldots$ be a sequence of non-negative independent copies of stochastic process $\{Y(x): x \in \chi\}$ with continuous sample paths. If there are such continuous functions $c_{n}>0$ and $d_{n} \in \mathbb{R}$ that marginal process $\{Z(x): x \in \chi\}$ 
defined as

$$
\frac{\max _{i=1, \ldots, n} Y_{i}(x)-d_{n}(x)}{c_{n}(x)} \rightarrow Z(x), \quad x \in \chi, \quad n \rightarrow \infty
$$

is non-degenerate, then $\{Z(x): x \in \chi\}$ is max-stable process. For the consistency of this theorem with one-dimensional case it is considered that marginal distribution $\{Z(x): x \in \chi\}$ in its condition must be distributed according to GEV.

Their spectral representation [4] has the following form:

$$
Z(x)=\max _{i \geqslant 1} \zeta_{i} Y_{i}(x), \quad x \in \chi,
$$

where $\left\{\zeta_{i}: i \geqslant 1\right\} \ldots$ are points of the Poisson process at $\ldots(0, \infty)$ and $Y_{1}, Y_{2}, \ldots$ is a sequence of non-negative independent copies of stochastic process $\{Y(x): x \in \chi\}$ such that $\mathbb{E}\{Y(x)\}=1$ for all $x \in \chi$. Points $\left\{\zeta_{i}: i \geqslant 1\right\}$ in the spectral characterization are radii while the stochastic processes $\left\{Y_{i}(x): i \geqslant 1\right\}$ are angles. Further, four main families of max-stable processes will be considered:

1) Smith process [5]:

$$
Z(x)=\max _{i \geqslant 1} \zeta_{i} \varphi\left(x-U_{i} ; 0, \Sigma\right), \quad x \in \chi
$$

2) Schlather process [6]:

$$
Z(x)=\sqrt{2 \pi} \max _{i \geqslant 1} \zeta_{i} \max \left\{0, W_{i}(x)\right\}, \quad x \in \chi ;
$$

3) Brown-Resnick process [4]:

$$
Z(x)=\max _{i \geqslant 1} \zeta_{i} \exp \left\{\left\{W_{i}(x)-\gamma(x)\right\}\right\}, \quad x \in \chi ;
$$

4) Extremal-t process [7]:

$$
Z(x)=c_{\nu} \max _{i \geqslant 1} \zeta_{i} \max \left[0, W_{i}(x)\right]^{\nu}, \quad x \in \chi .
$$

Here, the Brown-Resnick process is characterized by Gaussian stationary process $W_{i}(x)$ with variogram $\gamma(x)$.

It is possible to derive a formula for finite-dimensional distribution $\{Z(x): x \in \chi\}$ from spectral characterization. For each $x=\left(x_{1}, \ldots, x_{k}\right) \in \chi^{k}, k \geqslant 1$ and $z=z\left(z_{1}, \ldots, z_{k}\right) \in$ $(0, \infty)^{k}$ we obtain next formula:

$$
\begin{aligned}
\operatorname{Pr}\{Z(z) \leqslant z\}= & \operatorname{Pr}\left[\text { No observation }(\zeta, Y) \in \Phi: \zeta Y\left(x_{j}\right)>Z_{j} \text { for } j \in \overline{1, k}\right]= \\
& =\exp \left[-\int_{0}^{\infty} \operatorname{Pr}\left\{\zeta>\min _{j=\overline{1, k}} \frac{z_{j}}{Y\left(x_{j}\right)}\right\} \zeta^{-2} d \zeta\right]=\exp \left\{-V_{x}\left(z_{1}, \ldots, z_{k}\right)\right\},
\end{aligned}
$$

where function $V_{x}\left(z_{1}, \ldots, z_{k}\right)$ is

$$
V_{x}\left(z_{1}, \ldots, z_{k}\right)=\mathbb{E}\left\{\max _{j=1, k} \frac{Y\left(x_{j}\right)}{z_{j}}\right\} .
$$

It fully describes the joint distribution $Z(x)$ and is called exponential function. 
It is obvious from the formula above that

$$
V_{x}(z, \ldots, z)=\frac{\theta(x)}{z}, \quad \theta(x)=\mathbb{E}\left\{\max _{j=1, k} Y\left(x_{j}\right)\right\} .
$$

Function $\theta(x)$ is called $k$-dimensional extremal coefficient [8] and represents total dependence measure between elements of random vector $Z(x)$. Due to independence of radial and angular components of the multidimensional extreme value the extremal coefficient doesn't depend on the radius, that is, from $z$ in $V_{x}(z, \ldots, z)$ and shows relation we are interested in.

We focus on the two-dimensional case and define the function of the extremal coefficient:

$$
\theta: h \mapsto \mathbb{E}[\max \{Y(x), Y(x+h)\}] .
$$

Extremal coefficient function takes values in the interval $[1,2]$, where the smallest value corresponds to complete dependence, and the largest corresponds to complete independence. For these two cases we obtain

$$
\begin{aligned}
& \operatorname{Pr}\{Z(x+h) \leqslant z \mid Z(x) \leqslant z\}=\operatorname{Pr}\{Z(x+h) \leqslant z\}^{\theta(h)-1}= \\
& = \begin{cases}1 & \text { (complete dependence) } \\
\operatorname{Pr}\{Z(x+h) \leqslant z\} & \text { (complete independence) }\end{cases}
\end{aligned}
$$

It is important to note that the calculation of the exponential function for $k>2$ can be difficult [9], therefore the consideration of finite-dimensional distributions of max-stable processes is mostly reduced to the two-dimensional case.

Example of spatial dependence measurement is shown in Fig. 1; here we plot pairwise f-madogram and extremal coefficient to show how dependence changes with distance.

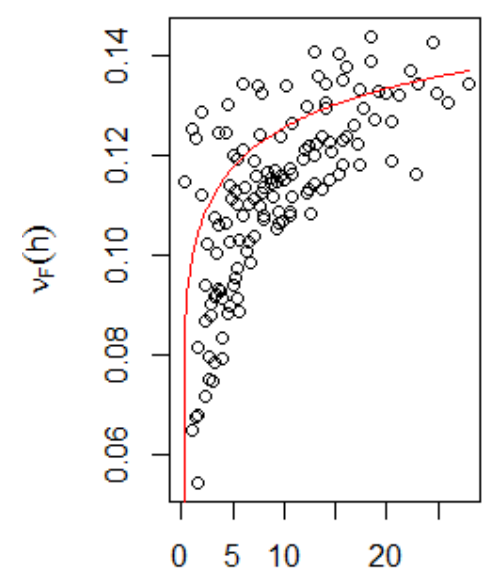

$\mathrm{h}$

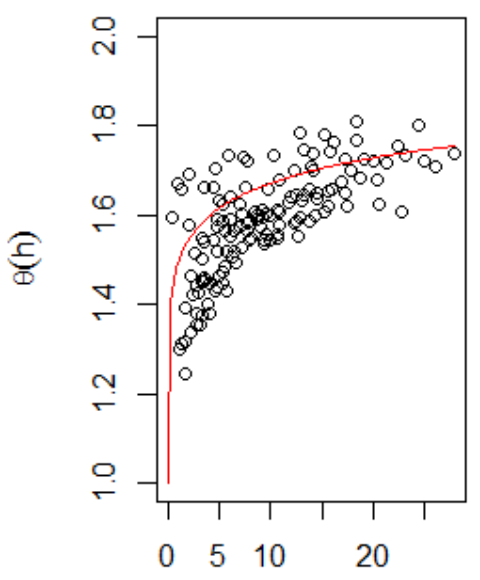

$\mathrm{h}$

Figure 1. Pairwise F-madogram (left panel) and extremal coefficient (right panel) for the best fitting max-stable process for our data (that will be shown below).

Distance between stations can be calculated as Distance $\approx h \cdot 111 \mathbf{k m}$ 


\section{Modeling of Extreme Precipitation Spatial Fields}

In this study precipitation data of the All-Russian Research Institute of Hydrometeorological Information — the World Data Center of the Russian Federation is used, which show monthly precipitation in 14 cities of the European part of Russia. The data is freely available (on the website http://aisori.meteo.ru/ClimateR) and is represented by a set of tables (a separate table for each city); each table contains daily rainfall value for the period 1966-2016 years. Thus, we face not only the problem of analyzing the statistical properties of one-dimensional time series for each station, but also the problem of model development that contains spatial structure of the statistical relationships in various locations [10].

Preliminary analysis of empirical data distribution properties in observed locations showed significant deviations of their statistical properties from the Gaussian distribution. It is for this reason that the use of GEV is justified, yet we need to evaluate the quality of fitting our data with GEV models. Diagnostic plots that are shown in Fig. 2 help us with that.
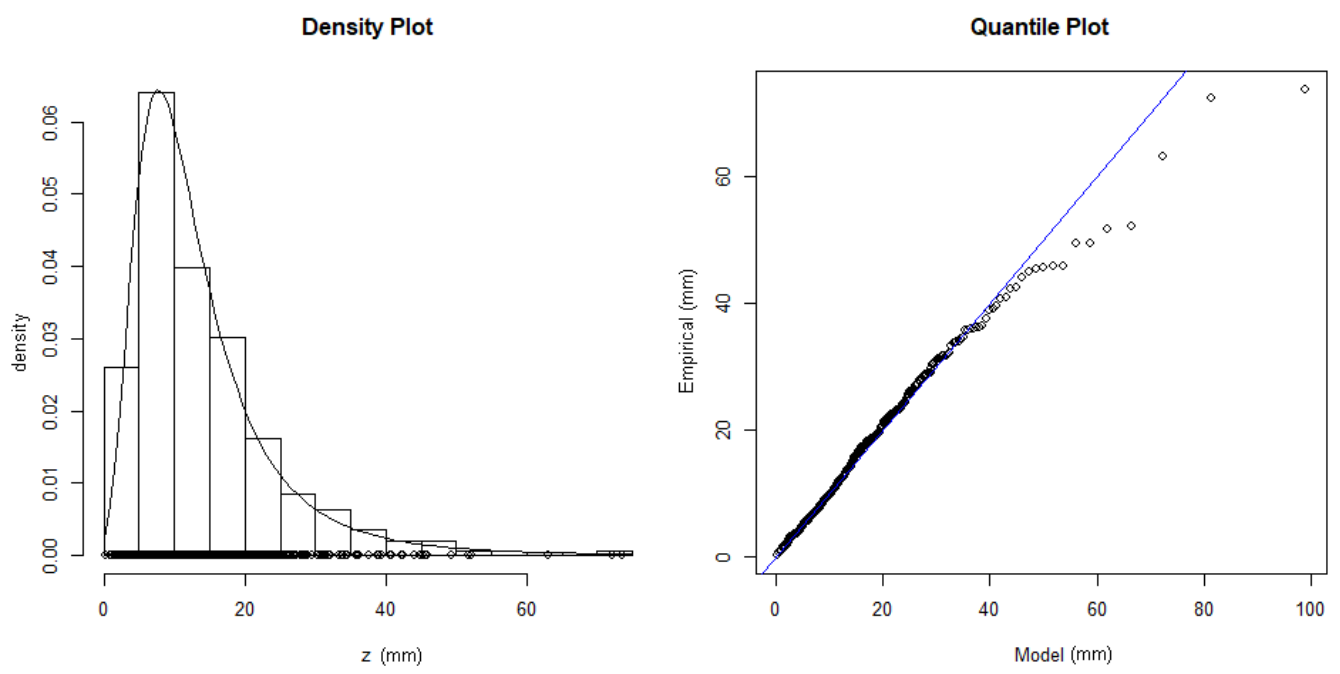

Figure 2. Diagnostic plots for GEV distribution in Ryazan (density plot and quantile plot)

Then GEV parameters were found for each city, they are shown in Table 1.

Developing trend surfaces for GEV parameters is important next step in our research because it might help us to estimate GEV parameters at any point of the field under study. It is important to note that the form parameter $\xi$ should be constant since it is the one that determines the model behaviour; position and scale parameters depend on the spatial coordinates, therefore they include latitude, longitude and their joint contribution. Thus, selection is made among models described as

$$
\begin{gathered}
\mu(s)=\beta_{\mu, 0}+\beta_{\mu, 1} \operatorname{lon}(s)+\beta_{\mu, 2} \operatorname{lat}(s)+\left[\beta_{\mu, 3} \cdot \operatorname{lon}(s) \cdot \operatorname{lat}(s)\right] \\
\sigma(s)=\beta_{\sigma, 0}+\left[\beta_{\sigma, 1} \operatorname{lon}(s)+\beta_{\sigma, 2} \operatorname{lat}(s)+\beta_{\sigma, 3} \cdot \operatorname{lon}(s) \cdot \operatorname{lat}(s)\right] \\
\xi(s)=\beta_{\xi, 0} .
\end{gathered}
$$

Table 2 shows the results of calculations, the choice of the best model is made using the Takeuchi information criterion (TIC) [11]. 
GEV parameters in observed locations (location $\mu$, scale $\sigma$, shape $\xi$ )

\begin{tabular}{|l|c|c|c|}
\hline Station (City) & $\mu$ & $\sigma$ & $\xi$ \\
\hline St. Petersburg & 39.764 & 22.911 & 0.059 \\
Pskov & 40.072 & 22.882 & 0.077 \\
Zheleznodorozhny & 40.891 & 24.541 & 0.037 \\
Smolensk & 42.843 & 25.261 & 0.09 \\
Bryansk & 40.268 & 24.644 & 0.028 \\
Kostroma & 36.57 & 22.254 & 0.073 \\
Pereslavl-Zalessky & 36.252 & 21.984 & 0.092 \\
Nizhny Novgorod & 39.389 & 23.786 & 0.034 \\
Mozhaysk & 38.547 & 23.755 & 0.097 \\
Moscow VDNH & 43.327 & 25.309 & 0.017 \\
Kolomna & 33.606 & 20.851 & 0.098 \\
Ryazan & 33.546 & 20.801 & 0.107 \\
Tambov & 30.413 & 20.217 & 0.08 \\
Penza & 32.414 & 21.085 & 0.048 \\
\hline
\end{tabular}

Table 2

Comparison of 4 models of trend surfaces for GEV parameters. The best model is chosen by the least value of TIC

\begin{tabular}{|l|c|}
\hline GEV Trend Surface & TIC \\
\hline$\hat{\mu}(s)=36.15+0.001 \cdot \operatorname{lat}(s)$ & \\
$\hat{\sigma}(s)=24.94-0.05 \cdot \operatorname{lon}(s)$ & 96840.95 \\
$\hat{\xi}(s)=0.06803$ & \\
\hline$\hat{\mu}(s)=-124.67+2.89 \cdot \operatorname{lon}(s)+3.07 \cdot \operatorname{lat}(s)-0.06 \cdot \operatorname{lon}(s) \operatorname{lat}(s)$ & \\
$\hat{\sigma}(s)=22.7$ & 96768.01 \\
$\hat{\xi}(s)=0.06956$ & \\
\hline$\hat{\mu}(s)=-123.67+2.87 \cdot \operatorname{lon}(s)+3.09 \cdot \operatorname{lat}(s)-0.06 \cdot \operatorname{lon}(s) \operatorname{lat}(s)$ & \\
$\hat{\sigma}(s)=-12.42+0.63 \cdot \operatorname{lon}(s)+0.73 \cdot \operatorname{lat}(s)-0.01 \cdot \operatorname{lon}(s) \operatorname{lat}(s)$ & 96741.95 \\
$\hat{\xi}(s)=0.06924$ & \\
\hline$\hat{\mu}(s)=52.9160-0.2064 \cdot \operatorname{lon}(s)-0.1261 \cdot \operatorname{lat}(s)$ & \\
$\hat{\sigma}(s)=30.298-0.114 \cdot \operatorname{lon}(s)-0.045 \cdot \operatorname{lat}(s)$ & 96797.6 \\
$\hat{\xi}(s)=0.06768$ & \\
\hline
\end{tabular}

Finally, we compare the various models of max-stable processes [12]. The Table 3 below shows various families of processes and correlation functions are given in parentheses. The best model corresponds to the smallest value of TIC. We don't consider comparing Smith model $[13,14]$ with presented ones because, despite being easy to understand and even easier to implement, it's quite ineffective in terms of modeling and fitting real environmental problems. 5 out of 7 models belong to Schlather family that can be explained by its popularity in comparison with more complex Brown-Resnick and Extremal-t processes yet last ones show better results [15]. Their modeling and fitting are still very consuming, both in terms of time and in terms of computing resources.

The best model is an extremal-t process with the Whittle-Matern correlation function. 
Results of max-stable processes' parameters estimating

Table 3

\begin{tabular}{|l|l|l|}
\hline Model & Parameters & TIC \\
\hline Brown-Resnick & $\begin{array}{l}\text { nugget }=0.4543 \\
\text { range }=6.4889 \\
\text { smooth }=0.7099\end{array}$ & 454911.7 \\
\hline $\begin{array}{l}\text { Schlather } \\
\text { (Whittle-Matern) }\end{array}$ & $\begin{array}{l}\text { nugget }=3.97 \cdot 10^{-5} \\
\text { range }=7.569 \cdot 10 \\
\text { smooth }=8.006 \cdot 10^{-2}\end{array}$ & 455315.8 \\
\hline $\begin{array}{l}\text { Schlather } \\
\text { (Cauchy) }\end{array}$ & $\begin{array}{l}\text { nugget }=0.4543 \\
\text { range }=6.4889 \\
\text { smooth }=0.7099\end{array}$ & 455151.4 \\
\hline $\begin{array}{l}\text { Schlather } \\
\text { (Power Exponential) }\end{array}$ & $\begin{array}{l}\text { nugget }=0.4679 \\
\text { range }=9.6612 \cdot 10 \\
\text { smooth }=2.0\end{array}$ & 455170.3 \\
\hline $\begin{array}{l}\text { Schlather } \\
\text { (Bessel) }\end{array}$ & $\begin{array}{l}\text { nugget }=0.4655 \\
\text { range }=0.4309 \\
\text { smooth }=120.2719\end{array}$ & 455170.9 \\
\hline $\begin{array}{l}\text { Schlather } \\
\text { (Generalized Cauchy) }\end{array}$ & $\begin{array}{l}\text { nugget }=0.4513 \\
\text { range }=6.9826 \\
\text { smooth }=1.5525 \\
\text { smooth2 }=2.0\end{array}$ & 455155.1 \\
\hline $\begin{array}{l}\text { Extremal-t } \\
\text { (Whittle-Matern) }\end{array}$ & $\begin{array}{l}\text { nugget }=0.2552 \\
\text { range }=2.7715 \\
\text { smooth }=96.3061 \\
\text { df }=3.2056\end{array}$ & 454108.9 \\
\hline
\end{tabular}

\section{Discussion}

In this paper we propose using the extreme value theory methods for modeling daily maximum precipitation fields in the European part of Russia. Our approach consists in estimating parameters of one-dimensional extreme distributions (1) for each metering station and developing models of statistical dependence spatial structures with the use of max-stable processes for the entire measurement domain. Using the data of the All-Russian Scientific Research Institute of Hydrometeorological Information - World Data Center, the fields of precipitation of daily measurements converted into monthly maximum precipitation were studied in 14 cities of the European part of Russia for the period 1966-2016 years. Parameters of precipitation fields models were estimated using the censored method of pairwise maximum likelihood [16] which further allows us to simulate daily precipitation amount throughout the region. Various parametric families of max-stable processes are developed and their estimates are obtained. The best model is the t-extremal process with the parameters shown above (in Table 3).

Interpolation of precipitation values in unobservable regions adjacent to the observed ones is usually solved by kriging [17] but despite the fact that this yields the optimal result for Gaussian processes, it can give erroneous forecasts for extreme values due to the unsuitability of the Gaussian model for the data. Approach that uses conditional max-stable simulation [18] is more suitable for these purposes. 
Proposed approach can be used in other areas where spatial modeling of extreme values and processes is required. The models of the max-stable processes used by us are also suitable for time scales in which precipitation measurements are stationary series. However the influence of estimation errors' autocorrelation increases in case of more frequent measurements and then it is necessary to develop models of space-time dependence structures $[19,20]$. This is one of the directions for the further development of this work.

\section{References}

1. V. A. Akimov, A. A. Bykov, E. Y. Shchetinin, Introduction to Extreme Value Statistics and Its Applications, FGU "All-Russian research institute on problems of civil defence and emergencies of Emergency Control Ministry of Russia", Moscow, 2009, in Russian.

2. L. de Haan, A. Ferraria, Extreme Value Theory: an Introduction, Springer-Verlag, New York, 2006.

3. R.-D. Reiss, M. Thomas, Statistical Analysis of Extreme Values with Applications to Insurance, Finance, Hydrology and Other Fields, Birkhauser, Basel, 2007.

4. B. M. Brown, S. I. Resnick, Extreme Values of Independent Stohastic Processes, Journal of Applied Probability 14 (1977) 732-739.

5. J. Smith, A. Karr, A Statistical Model of Extreme Storm Rainfall, Journal of Geoghysical Research: Atmospheres 95 (1990) 2083-2092.

6. M. Schlather, Models for Stationary Max-Stable Random Fields, Extremes 5 (1) (2002) 33-44.

7. T. Opitz, Extremal t Processes: Elliptical Domain of Attraction and a Spectral Representation, Journal of Multivariate Analysis 122 (2013) 409-413.

8. A. Aghakouchak, N. Nasrollahi, Semi-parametric and Parametric Inference of Extreme Value Models for Rainfall Data, Water Resources Management 24 (6) (2010) 1229 1249.

9. A. C. Davison, S. A. Padoan, M. Ribatet, Statistical Modeling of Spatial Extremes, Statistical Science 27 (2) (2012) 161-186.

10. S. Coles, An Introduction to Statistical Modeling of Extreme Values, Springer-Verlag, London, 2001.

11. J. Galambos, Order Statistics of Samples from Multivariate Distributions, Journal of the American Statistical Association 70 (351) (1975) 674-680.

12. R. Davis, C. Kluppelberg, C. Steinkohl, Max-Stable Processes for Modeling Extremes Observed in Space and Time, Journal of the Korean Statistical Society 42 (3) (2013) $399-414$.

13. P. Embrechts, F. Lindskog, A. McNeil, Modelling Dependence with Copulas and Applications to Risk Management, Elseiver, 2001.

14. P. Diggle, P. J. Ribeiro, Model-Based Geostatistics, Springer-Verlag, New York, 2007.

15. Z. Kabluchko, M. Schlather, L. de Haan, Stationary Max-Stable Fields Associated to Negative Definite Functions, The Annals of Probability 37 (5) (2009) 2042-2065.

16. S. Padoan, M. Ribatet, S. Sisson, Likelihood-Based Inference for Max-Stable Processes, Journal of the American Statistical Association (Theory \& Methods) 105 (489) (2010) 263-277.

17. J. Beirlant, Y. Goegebeur, J. Teugels, J. Segers, Statistics of Extremes: Theory and Applications, Wiley, New York, 2004.

18. C. Dombry, F. Eyi-Minko, M. Ribatet, Conditional Simulation of Max-Stable Processes, Biometrika 100 (1) (2013) 111-124.

19. G. Frahm, M. Junker, R. Schmidt, Estimating the Tail-Dependence Coefficient: Properties and Pitfalls, Insurance: Mathematics and Economics 37 (1) (2005) 80-100.

20. R. Schmidt, U. Stadtmuller, Non-Parametric Estimation of Tail Dependence, Scandinavian Journal of Statistics 33 (2) (2006) 307-335. 
УДК 519.246.5

DOI: $10.22363 / 2312-9735-2018-26-1-74-83$

\title{
Моделирование полей экстремальных осадков на территории Европейской части России
}

\author{
Е. Ю. Щетинин* ${ }^{*}$ Н. Д. Рассахан ${ }^{\dagger}$ \\ * Всероссийский научно-исследовательский институт \\ по проблемам гражданской обороны и чрезвычайных ситуащий МЧС России \\ ул. Давыдковская, д. 7, Москва, Россия, 121352 \\ ${ }^{\dagger}$ Кафедра прикладной математики \\ Московский государственный технологический университет «Станкин» \\ Вадковсий переулок, д. За, Москва, Россия, 127055
}

В настоящей работе исследована проблема моделирования пространственно-временных статистических структур экстремального типа с использованием процессов устойчивых максимумов. Рассмотрена теория одномерных экстремальных величин и её расширение до двумерного случая, для чего вводятся процессы устойчивых максимумов.

Предложена математическая модель процесса устойчивых максимумов и представлены основные параметрические семейства - Шлатера, Смита, Брауна-Резника, Экстремальное-t. При помощи модификации метода максимального правдоподобия, а именно с использованием парной функции правдоподобия, были получены оценки параметров для каждой из моделей, эффективность которых была затем сравнена при помощи информационного критерия Такеучи (TIC).

Полученные модели согласуются с классической теорией экстремальных значений и позволяют рассматривать устойчивую пространственную зависимость осадков. Эффективность предложенных моделей проверялась на ежедневных данных по суммарным осадкам, зарегистрированных на 14 станциях в центральной европейской части России на период 1966-2016 гг.: сравниваются статистические модели из различных семейств, подходящих для пространственных экстремумов, после чего выбираются те, которые наилучшим образом описывают существующие данные. Этот метод можно использовать и в других приложениях для создания симуляций, необходимых для гидрологических моделей и, в частности, для создания пространственно-неоднородных осадков над водосборами. Было показано, что наилучшей моделью оказался экстремальный-t процесс с корреляционной функцией Уиттла-Матерна.

Ключевые слова: пространственное моделирование, экстремальные осадки, процессы устойчивых максимумов, теория экстремальных величин, пространственные структуры статистической зависимости, парная функция правдоподобия

\section{Литература}

1. Акимов В. А., Быков А. А., Щетинин Е. Ю. Введение в статистику экстремальных величин и ее приложения. - М.: ФГУ ВНИИ ГОЧС (ФЦ) МЧС России, 2009.

2. de Haan L., Ferraria A. Extreme Value Theory: an Introduction. - New York: Springer-Verlag, 2006.

3. Reiss R.-D., Thomas M. Statistical Analysis of Extreme Values with Applications to Insurance, Finance, Hydrology and Other Fields. - Basel: Birkhauser, 2007.

4. Brown B. M., Resnick S. I. Extreme Values of Independent Stohastic Processes // Journal of Applied Probability. — 1977. — Vol. 14. — Pp. 732-739.

5. Smith J., Karr A. A Statistical Model of Extreme Storm Rainfall // Journal of Geoghysical Research: Atmospheres. — 1990. — Vol. 95. — Pp. 2083-2092.

6. Schlather M. Models for Stationary Max-Stable Random Fields // Extremes. - 2002. Vol. 5, No 1. - Pp. 33-44.

7. Opitz T. Extremal t Processes: Elliptical Domain of Attraction and a Spectral Representation // Journal of Multivariate Analysis. - 2013. - Vol. 122. - Pp. 409-413.

8. Aghakouchak A., Nasrollahi N. Semi-Parametric and Parametric Inference of Extreme Value Models for Rainfall Data // Water Resources Management. - 2010. Vol. 24, No 6. - Pp. 1229-1249. 
9. Davison A. C., Padoan S. A., Ribatet M. Statistical Modeling of Spatial Extremes // Statistical Science. — 2012. — Vol. 27, No 2. — Pp. 161-186.

10. Coles S. An Introduction to Statistical Modeling of Extreme Values. — London: Springer-Verlag, 2001.

11. Galambos J. Order Statistics of Samples from Multivariate Distributions // Journal of the American Statistical Association. - 1975. - Vol. 70, No 351. - Pp. 674-680.

12. Davis R., Kluppelberg C., Steinkohl C. Max-Stable Processes for Modeling Extremes Observed in Space and Time // Journal of the Korean Statistical Society. — 2013. Vol. 42, No 3. - Pp. 399-414.

13. Embrechts P., Lindskog F., McNeil A. Modelling Dependence with Copulas and Applications to Risk Management. - Elseiver, 2001.

14. Diggle P., Ribeiro P. J. Model-Based Geostatistics. - N.-Y.: Springer-Verlag, 2007.

15. Kabluchko Z., Schlather M., de Haan L. Stationary Max-Stable Fields Associated to Negative Definite Functions // The Annals of Probability. — 2009. — Vol. 37, No 5. — Pp. 2042-2065.

16. Padoan S., Ribatet M., Sisson S. Likelihood-Based Inference for Max-Stable Processes // Journal of the American Statistical Association (Theory \& Methods). 2010. - Vol. 105, No 489. - Pp. 263-277.

17. Statistics of Extremes: Theory and Applications / J. Beirlant, Y. Goegebeur, J. Teugels, J. Segers. - New York: Wiley, 2004.

18. Dombry C., Eyi-Minko F., Ribatet M. Conditional Simulation of Max-Stable Processes // Biometrika. - 2013. - Vol. 100, No 1. - Pp. 111-124.

19. Frahm G., Junker M., Schmidt R. Estimating the Tail-Dependence Coefficient: Properties and Pitfalls // Insurance: Mathematics and Economics. — 2005. — Vol. 37, No 1. — Pp. 80-100.

20. Schmidt R., Stadtmuller U. Non-Parametric Estimation of Tail Dependence // Scandinavian Journal of Statistics. - 2006. - Vol. 33, No 2. — Pp. 307-335.

(C) Shchetinin E. Yu., Rassakhan N.D., 2018

Для цитирования:

Shchetinin E. Yu., Rassakhan N.D. Modeling of Extreme Precipitation Fields on the Territory of the European Part of Russia // RUDN Journal of Mathematics, Information Sciences and Physics. - 2018. — Vol. 26, No 1. — Pp. 74-83. — DOI: 10.22363/23129735-2018-26-1-74-83.

\section{For citation:}

Shchetinin E. Yu., Rassakhan N.D. Modeling of Extreme Precipitation Fields on the Territory of the European Part of Russia, RUDN Journal of Mathematics, Information Sciences and Physics 26 (1) (2018) 74-83. DOI: 10.22363/2312-9735-2018-26-1-74-83.

\section{Сведения об авторах:}

Шетинин Евгений Юрьевич - профессор, доктор физико-математических наук, ведущий научный сотрудник ФГБУ ВНИИ ГОЧС (ФЦ) (e-mail: riviera-molto@ mail.ru, тел.: +7 (917)539-06-98)

Рассахан Никита Дмитриевич - магистрант кафедры прикладной математики ФГБОУ ВО МГТУ «Станкин» (e-mail: rassahan@gmail.com, тел.: +7 (906)095-02-87)

\section{Information about the authors:}

Shchetinin E. Yu. - professor, Doctor of Physical and Mathematical Sciences, Leading Researcher of FGU "All-Russian research institute on problems of civil defence and emergencies of Emergency Control Ministry of Russia" (e-mail: riviera-molto@mail.ru, phone: +7 (917)539-06-98)

Rassakhan N. D. - Master of Science of the Applied Mathematics Department, MSTU "Stankin" (e-mail: rassahan@gmail.com, phone: +7 (906)095-02-87) 